http://jurnal.fkip-uwgm.ac.id/index.php/Script Script Journal: Journal of Linguistic and English Teaching

P-ISSN: 2477-1880; E-ISSN: 2502-6623 April 2017, Vol. 2 No. 1

\begin{tabular}{|r|c|c||}
\hline Received: April 2017 & Accepted: April 2017 & Published: April 2017 \\
\hline \hline Article DOI: $\underline{\text { http://dx.doi.org/10.24903/sj.v2i1.78 }}$ \\
\hline
\end{tabular}

\title{
The Effects Of Implementing Workshop On Radio Broadcasting Class Towards Students Speaking Ability
}

\author{
Nini Wahyuni \\ Politeknik Negeri Padang \\ ni2_wa@yahoo.com \\ Sumira \\ Politeknik Negeri Padang \\ sumiradoano@gmail.com
}

\begin{abstract}
This research discuss about The Effects of Implementing Workshop on Radio Broadcasting Class Towards Students Speaking Ability. The purposes are to know whether there is improvement in student speaking ability while conducting Workshop on Radio Broadcasting. The participants of this research are English Department students of State Polytechnic of Padang who attend Workshop on Broadcasting course in academic period 2015-2016. The observation data shows that the students' articulation, intonation, and expression in delivering the radio program are become better because they trained to speak clearly and in various way. Meanwhile, the questionnaire data shows that there were $60 \%$ students agree that Workshop on Radio Broadcasting class is important to improve their speaking ability, $68 \%$ students agree that they can improve their grammar, $72 \%$ students agree that they can improve their vocabulary, 56\% students agree that they can express their idea, and their articulation and speaking speed become better, $72 \%$ students agree that they can speak more fluent and their accuracy and 60\% students agree that by practicing as a radio announcer, news reader and reporter, their self confident is improve. The average score for the students' accent was 2,96, means that they have "Foreign accent" requires concentrated listening, and mispronunciations lead to occasional misunderstanding and apparent errors in grammar or vocabulary. The average score for grammar was 3,08. For vocabulary, the average score was 3,04. For Fluency, the average score was 3,00. Finally, for comprehension, the average score was 3,16.
\end{abstract}

Keywords: effect; radio broadcasting; speaking ability 


\section{INTRODUCTION}

State Polytechnic of Padang is one vocational institution in Padang, West Sumatera. It has 12 Diploma-3 study program and 7 Diploma-4 study program which spread over 7 studies. One of the newest study programs is English Department that is established in 2009. Since its present, English Department has already provided their students with two valuable skills, namely Translation and Broadcasting. In Translation, students are prepared to be a good and professional translator. Meanwhile, in Broadcasting, the students prepared to be a good and professional broadcaster.

In English Department, the Broadcasting course is divided into two main subjects; namely TV and Radio Broadcasting. Especially for Radio Broadcasting, the students learn any kind of issues such as the theory of radio broadcasting, the radio program, the announcing skills, the radio stations regulation, the radio stations management, and etc. After taking this course, they should proceed to Workshop on Radio Broadcasting class. For this course, students get a chance to be a professional radio announcer at Polytechnic FM. Moreover, they get a regular schedule to guide and host a radio program.

Both of these theoretical and practical class are taught and guided by qualified teachers who have experience in radio broadcasting for many years. Therefore, students should have a good qualification as a radio announcer and they should have a good communication skill in English speaking. However, the effect of the Workshop on Radio Broadcasting class towards student speaking ability is unknown yet. During this time, the speaking ability of the students still need to be improved because it was found that some of the students cannot speak English fluently. It can be seen from their performance while having a discussion or doing a role play in class. Moreover, the speaking activities are usually done in the classroom. Therefore, the English communication seems not real for them.

Based on the problem, the researcher interested to conduct a research about the effect of the implementing Workshop on Radio Broadcasting class towards students speaking ability. It assumes that the students need a media to make them practice their English more and in a real situation. Through Workshop on Radio Broadcasting class, students learn how to deliver the news, how to conduct a talk show, how to report the news, how to create an advertisement and features and these activities will be broadcast directly through radio streaming, thus the listener from various area can listen Polytechnics FM that is broadcast by English Department students of State Polytechnic of Padang. 
The aims of this research is to find whether the implementation of Workshop on Radio Broadcasting class give effect to the students Speaking ability. Moreover, this research can be used as a way to measure the students speaking achievement by using Workshop on Radio Broadcasting class. In addition, this research is hoped can give many benefits for many aspects. First, for English Department lecturers, this research can be used to maximize the teaching learning role in Workshop on Radio Broadcasting class. Meanwhile, for the students of English Department, it can be used as a way to improve their speaking ability in English. Finally, for English Department, the result of the research can be used as consideration in designing the curriculum.

\section{Radio Broadcasting}

As general, radio defines as a communication tool to deliver information from one place to another. Meanwhile, broadcasting means to communicate or transmit ( a signal, a message, or content such as audio or video programming) to numerous recipients simultaneously over a communication networks. Therefore, radio broadcasting can defines as sending transmission to a large audience through radio.

According to d' Ecclesia (2013), radio is a means of communication which based on music and words to entertain and inform the public. In addition, radio develops the "image" through several elements; namely music, programming, sounds effects, hosts, jingles, theme songs and etc. All of the elements are fundamental in carrying out the company's sound image. McLeish (in Mohammed, 2013) divides the characteristic of radio as follows:

1. The Speed of Radio as Information Sisseminator. It means that radio has an enormous speed because it is a medium of sound, to impart the latest news or any message, it does not need to wait for the printing processes like that of newspaper or to wait for the processes of picture taking and editing like that of television.

2. Radio Speaks to Million. It means that radio gives much information to the listeners. Even a person cannot read a newspaper or read caption or text on television, they can listen to program or news in any language on the radio.

3. Radio Speaks to the Individual. The radio speaks to the each of listener as an individual audience. It can create greater impact and involvement to the listener.

4. Radio Makes Mental Pictures. Radio employs only sounds (or sounds and pause/silence to be precise) and uses them to their maximum effect to provide 
the whole pictures of the story. Therefore, the listeners have to use their imagination to interpret a story.

5. Radio Has No Boundaries. It means that radio signals go across mountains and oceans with no difficulties.

6. The Simplicity of Radio. Radio is totally dependent on sounds, the medium has simplicity in the whole processes of massage production- from reporting to broadcast.

7. Radio is cheap. It means the price of radio is affordable and inexpensive. Therefore, it can be a prime electronic medium of the poor.

8. The personality of Radio. Radio messages are often delivered by the human voice and due to differences that come from geographical location and social status, different people will definitely have different accents and dialects. It is, therefore, "important that all kinds of voices are heard and not just those of professional"

9. Radio for change. It acts as a multiplier of change.

10. It is a powerful medium. It used to speed up information, to exchange ideas and make discussions.

Based on the explanation above, it can conclude that radio is a mass communication media to deliver information. Radio is fast, simple and inexpensive tools, therefore everyone can receive and listen to the radio. As the communication medium, radio also can be used as teaching learning media. Through radio, students can learn how to get information (listening), how to broadcast information (speaking), how to deliver the information/ message (reading) and how to make the radio script (writing). In Workshop on Radio Broadcasting class, students are guided to be a professional announcer. Moreover, they learn and practice as radio announcer, reporter, host, music director, production house, and etc for 1 semester (about 6 months). All of those parts can be a valuable experience for the students. They can improve their language skill in conducting each roles, especially in English.

\section{The Nature Speaking}

Speaking is the productive aural/ oral skill that consists of producing systematic verbal utterances to convey meaning (Nunan, 2003). It is a quite complex undertaking which involves using all the different level of language. Wallace, Stariba, and Welberg (2004) state that teachers have to consider these following ways in teaching speaking: 
1. Provide students with opportunities for practicing specific speaking skills. Students improve their formal speech when teachers provide insights on how to organize their ideas for presentation.Students can give better speeches when they can organize their presentation in a variety of different ways, including sequentially, chronologically and thematically. They need practice in organizing their speech around problems and solutions, causes and results, and similarities and differences. After deciding about the best means of organization, they can practice speeches with another student or with the whole class.

2. Teach students to adapt their speech to specific situations. Learners need to know how speakers differ from one another and how particular circumstances call for different forms of speech. They can learn how speaking styles affect listeners. Thus, the rate of which they speak, the volume and the precision of pronunciation may differ substantially from one situation to another.

3. Provide opportunities to practice speaking before increasingly larger groups. Children, adolescents, and adults sometimes fear the challenge of sustained, formal speaking before large groups. Teachers can help reduce unrealistic fears by pointing out how common they are among people and what to do about them. Students can practice presenting information, answering questions and holding group discussions.

According to Brown (2001: 270), in implementing speaking in the interactive classroom, teachers should be able to make their students deal with both interpersonal (sometimes referred to as interactional) and transactional dialogue and they are able to converse with a total stranger as well as someone with whom they are quite familiar. Richard (in Brown 2001) offers some features of conversation that can receive a specific focus in classroom instruction such as how to use conversation for both transactional and interactional purposes, how to produce both short and long turns in conversation, how to initiate and respond to talk on a broad range of tropics, and etc.

Based on the explanation, radio broadcasting can be a great way in making students to speak because in radio broadcasting students have opportunity to practice specific speaking skill, such as how to speak in radio, how to deliver the news, how to conduct a talk show, how to report the news, and etc. Moreover, teacher can teach students to adapt their speech to 
specific situation that is radio broadcasting. It needs a special skill in which the students have to be able to broadcast without seeing the listener/ target audience directly.

\section{Speaking Assessment}

To know or to assess the students improvement while conducting radio broadcasting, it needs some speaking assessment criteria. It is used as the guidance in determining the students speaking improvement.According to Hughes (1989), there are some categories of speaking assessment criteria, as follows:

\section{Accent}

1. Pronunciation frequently unintelligible.

2. Frequent gross errors and a very heavy accent make understanding difficult, require frequent repetition.

3. "Foreign accent" requires concentrated listening, and mispronunciations lead to occasional misunderstanding and apparent errors in grammar or vocabulary.

4. Marked "foreign accent" and occasional mispronunciation which do not interfere with understanding.

5. No conspicuous mispronunciation, but would not be taken for a native speaker.

6. Native pronunciation, with no trace of "foreign accent"

\section{Grammar}

1. Grammar almost entirely inaccurate phrases.

2. Constant errors showing control of very few major patterns and frequently preventing communication.

3. Frequent errors showing some major pattern uncontrolled and causing occasional irritation and misunderstanding.

4. Occasional errors showing imperfect control of some pattern but no weakness that causes misunderstanding.

5. Few errors, with no patterns of failure.

6. No more than two errors during the interview.

\section{Vocabulary}

1. Vocabulary in adequate for even the simplest conversation.

2. Vocabulary limited to basic personal and survival areas (time, food, transportation, family, etc.)

3. Choice of words sometimes in accurate, limitations of vocabulary prevent discussion of some common professional and social topics. 
4. Professional vocabulary adequate to discuss special interests; general vocabulary permits discussion of any non-technical subject with some circumlocutions.

5. Professional vocabulary apparently as accurate and extensive as that of an educated native speaker.

6. Vocabulary apparently as accurate and extensive as that of an educated native speaker.

\section{Fluency}

1. Speech is so hating and fragmentary that conversation is virtually impossible.

2. Speech is very slow and uneven except for short or routine sentences.

3. Speech is frequently hesitant and jerky; sentences may be left uncompleted.

4. Speech is occasionally hesitant, with some unevenness caused by rephrasing and groping for words.

5. Speech is effortless and smooth, but perceptibly non-native in speech evenness.

6. Speech on all professional and general topics as effortless and smooth as native speakers.

\section{Comprehension}

1. Understands too little for the simplest type of conversation.

2. Understand only slow, very simple speech on common social and touristic topics; requires constant repetition and rephrasing.

3. Understand careful, somewhat simplified speech when engaged in dialogue, but may require considerable repetition and rephrasing.

4. Understand quite well normal educated speech when engaged in a dialogue, but requires occasional repetition or rephrasing.

5. Understand everything in normal educated conversation except for very colloquial or low-frequency items, or exceptionally rapid or slurred speech.

6. Understands everything in both formal and colloquial speech to be expected of an educated native speaker.

In this research, the improvement of students in English speaking also can seen from their accent, grammar, vocabulary, fluency, and comprehension. The assessment is done for 2 times by comparing their score in mid and final semester. The scoring is 1 for the lowest score, and six for the highest score. 


\section{METHODOLOGY}

\section{Research Design}

The design applied in this study is quantitative and qualitative research in which the data were collected through class observation, speaking assessment, and questionnaire. The data were analyzed descriptively.

\section{Population and Sample}

The population of this research was English Department students of State Polytechnic of Padang who attended Workshop on Radio Broadcasting class in academic year 2015/2016. There were two classes (2A and 2B) and each class consists of 22-24 students. The sample were taken randomly.

\section{Data Collection Instruments}

In this research, there were three instruments that were used in collecting the data, namely:

1. Observation

The observation was focus on finding the student progress especially in speaking. It was done in the studio radio of State Polytechnic of Padang during one semester. Before performing as radio announcer, the students are trained to speak and to read the script. They have to be ready with a radio script every meeting. While students practicing to read the script or conducting a radio program, the lectures will observe whether any improvement in student speaking ability. The observation results were collected through teachers' field notes.

2. Students' scores/ Assessment

This assessment was used to know the improvement on student speaking ability. The assessment comprise of accent, grammar, vocabulary, fluency, and comprehension and it was used a six-point scale for each part.

3. Questionnaire

It was used to know the student's response related to the effect of Workshop on the Radio Broadcasting class to their speaking ability. The questionnaire consists of ten statements and each of them has four responses; namely strongly agree, agree, disagree, and strongly disagree.

\section{Technique of Data Collection}

The data were collected during the Workshop on Radio Broadcasting class take place. First, the data were collected through class observation in which the researchers observed 
whether there is an improvement in the students speaking ability. Then, the students broadcast recording were assessed based on the speaking criteria level. Due to confirm the data from the observation and assessment results, the questioners were given to the students.

\section{Technique of Data Analysis}

The data from observation was analyzed qualitatively. Meanwhile, the data from speaking assessment and questionnaire were analyzed quantitatively through descriptive statistics analysis involving gathering and interpreting the data. For the observation, the data were collected through field note and photograph. Moreover, the data questionnaire used Likert Scale with four-point scale; strongly agree (4), agree (3), disagree (2), strongly disagree (1). Meanwhile, for the speaking assessment, it was used speaking criteria level that was proposed by Hughes (1989) with six-point scale. The criteria for speaking were accent, grammar, vocabulary, and fluency.

\section{FINDINGS}

\section{Observation}

The observation data were collected through field notes and photograph. The data were taken during the Workshop on Radio class. There were 16 meeting for each class and the classes were observed by the lecturers who have experience in radio broadcasting (senior broadcaster) and also English Department lectures. The observation result can be seen as the below:

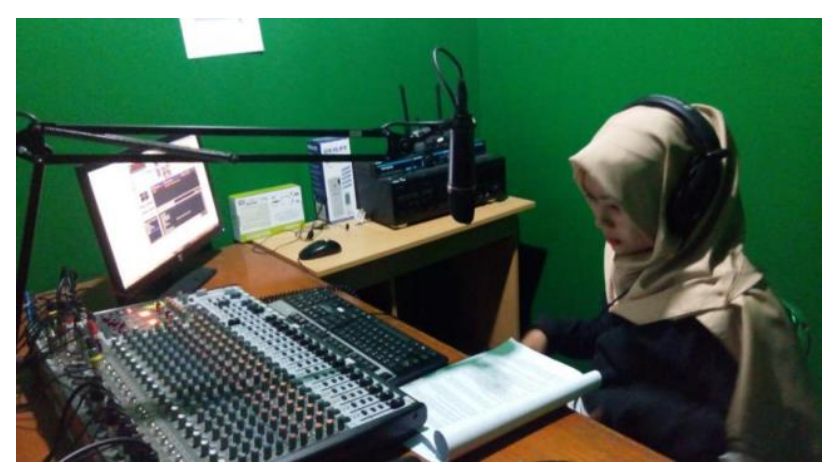

Figure 1. Reading the script

In each meeting, the students practiced their broadcasting skill as a Radio announcer. In this stage, the lectures observed their speaking ability. After they finished practicing the radio broadcast, the lecturers gave some feedback by giving comments and suggestions through field 
notes. Moreover, the lectures also observed the students' progress every week. The notes can be seen as the following

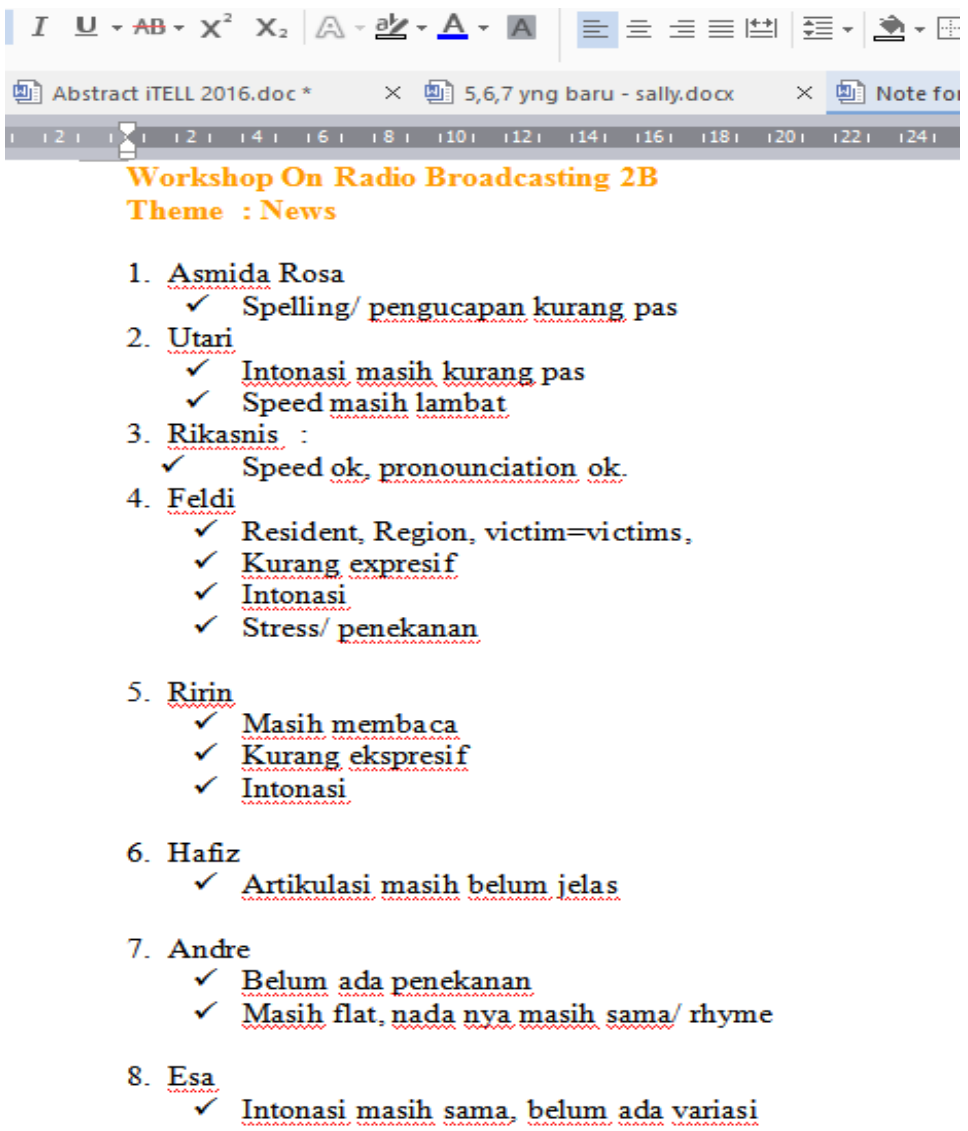

Figure 1. Field Notes (1)

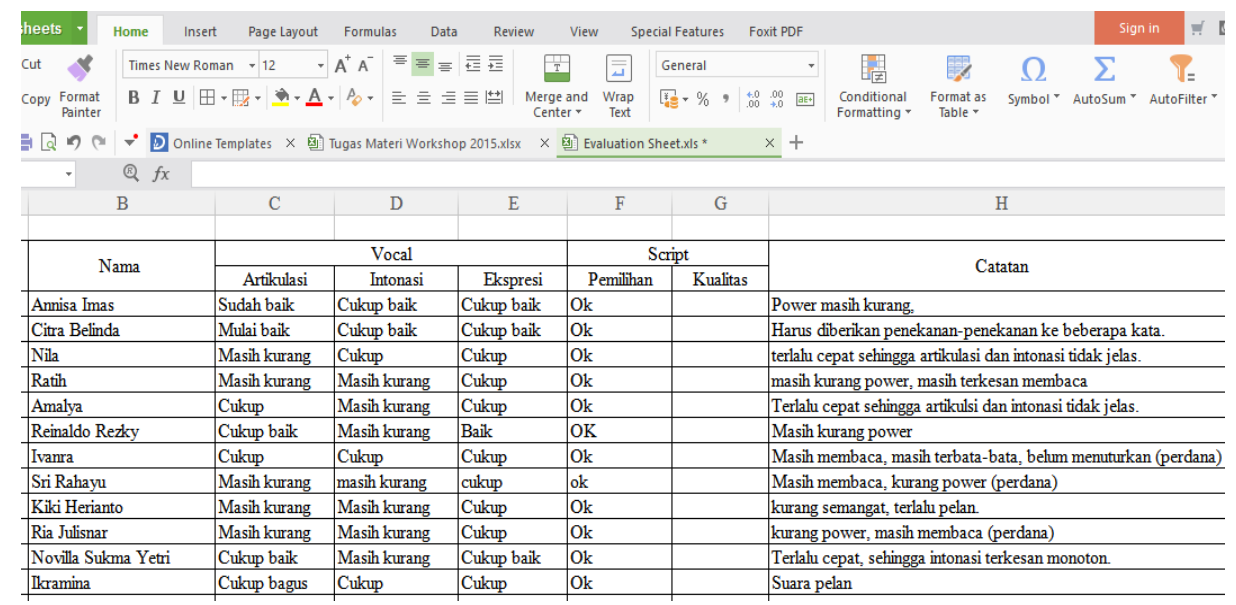

Figure 2. Field Notes (2)

The notes consist of comments and suggestions from the lecturers. They observed the students speaking improvement while conducting radio broadcasting. The observation was focused on the students' articulation, intonation, and expression. After reading the script, 
conducting a talk show, reporting news, or doing dialog with the informant, the lectures gave some comments or suggestion. The students have to pay to the lecturers' suggestion to avoid the same mistake in the further practice.

\section{Speaking Assessment}

The assessment were taken through Mid and Final Test. The speaking criteria level based on Hughes (1989) theory that consist of six-point scale; accent, grammar, vocabulary, fluency, and comprehension. The speaking assessment were taken while students practicing as a radio announcer. For mid semester assessment, the students hosted a radio program, while in final semester, they have to make a radio feature. The assessment results were compared to see whether any improvement or not. The speaking assessment results can be seen in the following diagram

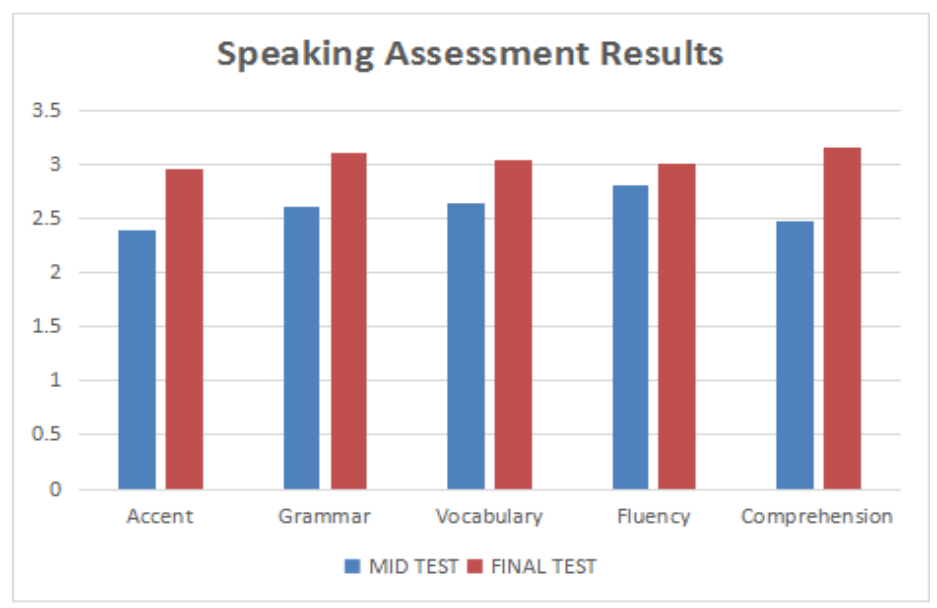

Figure 3 Speaking Assessment Results

From the bar chart, it can be seen that the score for mid and final assessment are different. The score for students accent, grammar, vocabulary, fluency, and comprehension were slightly improve, event the improvement was not really significant.

\section{Questionnaire}

The questionnaire consists of ten statement and the students have to choose strongly agree, agree, disagree, or strongly disagree to the statement. The total score for the questionnaire can be seen in the following table: 


\begin{tabular}{|c|c|c|c|c|}
\hline Statement & $\begin{array}{l}\text { Strongly } \\
\text { Disagree } \\
\text { (1) }\end{array}$ & $\begin{array}{l}\text { Disagree } \\
\text { (2) }\end{array}$ & $\begin{array}{l}\text { Agree } \\
\text { (3) }\end{array}$ & $\begin{array}{l}\text { Strongly } \\
\text { Agree } \\
\text { (4) }\end{array}$ \\
\hline $\begin{array}{l}\text { 1. Works hop on Radio Broadcasting } \\
\text { class is impartant to me becsuse it can } \\
\text { improve my speaking ability. }\end{array}$ & $\begin{array}{c}1 \\
(496)\end{array}$ & $\begin{array}{c}1 \\
(4 \%)\end{array}$ & $\begin{array}{c}15 \\
(6096)\end{array}$ & $\begin{array}{c}8 \\
(32 \%)\end{array}$ \\
\hline $\begin{array}{l}\text { 2. Through Workhop on Radio } \\
\text { Broadasting class, my grammar is } \\
\text { improve becsuse I train to speak in a } \\
\text { good structure as a radio announcer, } \\
\text { news resder, and reporter. }\end{array}$ & - & $\begin{array}{c}3 \\
(12 \%)\end{array}$ & $\begin{array}{c}17 \\
(6896)\end{array}$ & $\begin{array}{c}5 \\
(20 \%)\end{array}$ \\
\hline $\begin{array}{l}\text { 3. I can improve my vocabulary from } \\
\text { radio brosdcasting activities and I can } \\
\text { use it while I am on the air. }\end{array}$ & - & - & $\begin{array}{c}18 \\
(7296)\end{array}$ & $\begin{array}{c}7 \\
(280 \%)\end{array}$ \\
\hline $\begin{array}{l}\text { 4. I can express my ides better because } \\
\text { as announcer I train to explore my } \\
\text { thought for some radio program. }\end{array}$ & - & $\begin{array}{c}3 \\
(12 \%)\end{array}$ & $\begin{array}{c}14 \\
(5606)\end{array}$ & $\begin{array}{c}8 \\
(32 \%)\end{array}$ \\
\hline $\begin{array}{l}\text { 5. My articulation become better because } \\
\text { I train to speal clearly and } \\
\text { understandable as a radio announcer, } \\
\text { news reader, and reporter. }\end{array}$ & $\begin{array}{c}1 \\
(40 \%)\end{array}$ & $\begin{array}{c}2 \\
(8 \%)\end{array}$ & $\begin{array}{c}14 \\
(560 \%)\end{array}$ & $\begin{array}{c}8 \\
(32 \%)\end{array}$ \\
\hline $\begin{array}{l}\text { 6. My pronunciation is become better } \\
\text { because I train to pronounce the words } \\
\text { correctly as a radio announcer in } \\
\text { geveral radio program. }\end{array}$ & $\begin{array}{c}1 \\
(4 \%)\end{array}$ & $\begin{array}{c}2 \\
(8 \%)\end{array}$ & $\underbrace{11}_{(4496)}$ & $\mathrm{II}_{(4406)}$ \\
\hline $\begin{array}{l}\text { 7. My apeaking spead become better } \\
\text { because I train to pay attention to my } \\
\text { speaking spead as a radio announcers, } \\
\text { news reader, and reporter. }\end{array}$ & - & $\begin{array}{c}3 \\
(12 \%)\end{array}$ & $\begin{array}{c}14 \\
(5696)\end{array}$ & $\begin{array}{c}8 \\
(32 \%)\end{array}$ \\
\hline $\begin{array}{l}\text { 8. I can speak English more fluent after } \\
\text { practicing as a radio announcer in } \\
\text { several radio program. }\end{array}$ & $\begin{array}{c}1 \\
(49 \%)\end{array}$ & $\begin{array}{c}2 \\
(8 \%)\end{array}$ & $\begin{array}{c}18 \\
(72 \%)\end{array}$ & $\begin{array}{c}4 \\
(16 \%)\end{array}$ \\
\hline $\begin{array}{l}\text { 9. My speaking accuracy is become } \\
\text { better becsuse I train to be aware with } \\
\text { my speaking while practice as a radio } \\
\text { announcer, news reader and reporter. }\end{array}$ & - & $\begin{array}{c}2 \\
(8 \%)\end{array}$ & $\begin{array}{c}18 \\
(72 \%)\end{array}$ & $\begin{array}{c}5 \\
(20 \%)\end{array}$ \\
\hline $\begin{array}{l}\text { 10. I can improve my self confidence after } \\
\text { practicing as a radio announcer, news } \\
\text { reader, and reporter in Wonshop on } \\
\text { Broackasting class. }\end{array}$ & - & - & $\begin{array}{c}15 \\
(6096)\end{array}$ & $\begin{array}{c}10 \\
(40 \%)\end{array}$ \\
\hline
\end{tabular}

Table 1 Questionnaire Results

\section{DISCUSSION}

Observation. Based on the observation data, there were some improvement in students speaking ability. After practicing as a radio announcer for one semester (about five months), the students' articulation become better because they train to speak clearly. Moreover, their intonation more fluent, because they train to speak in various way. In addition, some of them can deliver the radio program in a good expression. Therefore, radio program more interesting and lively.

Speaking Assessment. Based on the Mid Test result, the average score for the student's accent was 2,4, it means that the students' accent is frequent gross errors and a very heavy accent makes understanding difficult, require frequent repetition. Moreover, the average score for grammar was 2,61, it means that students' grammar have constant errors showing control of very few major patterns and frequently preventing communication. For the Vocabulary, the average score was 2,64 , it means that students' vocabulary have limited to basic personal and survival areas. Meanwhile, the average score for the students' fluency was 2,81, it means that their speech is very slow and uneven except for short or routine sentences. Finally, for the 
students' comprehension, the average score was 2,4 , it means that they understand only slow, very simple speech on common social and topics; requires constant repetition and rephrasing.

In the Final Test results, it can be seen that there were some improvement, even the results did not increase significantly. The average score for the students' accent was 2,96. It means that they have "Foreign accent" requires concentrated listening, and mispronunciations lead to occasional misunderstanding and apparent errors in grammar or vocabulary. Meanwhile, the average score for grammar was 3,08. It means that students have frequent errors showing some major pattern uncontrolled and causing occasional irritation and misunderstanding.

For vocabulary, the average score was 3,04. It means that choice of words sometimes in accurate, limitations of vocabulary prevent discussion of some common professional and social topics. For Fluency, the average score was 3,00. It means that the speech is frequently hesitant and jerky; sentences may be left uncompleted. Finally, for Comprehension, the average score was 3,16 . it means that they understand careful, somewhat simplified speech when engaged in dialogue, but may require considerable repetition and rephrasing.

From the results, it can be concluded that the score for mid and final semester are different. The students final score are higher than their mid score. It can be assumed that the students can improve their speaking ability during conducting workshop on radio broadcasting, even though the improvement is not really significant.

Questionnaire. Based on the questionnaire data, there were $60 \%$ students agree that the class is important to improve their speaking ability. Some of them agree that the implementation of the class can improve their speaking ability such as $68 \%$ students agree that they can improve their grammar because they train to speak in a good structure as a radio announcer, news reader, and reporter and then $72 \%$ students agree that they can improve their vocabulary from radio broadcasting activities and they can use it while on the air. Moreover, $56 \%$ students agree that they can express their idea, and their articulation and speaking speed become better because they train to explore their thought for some radio program and they train to speak clearly, understandable and should pay attention to their speaking speed as a radio announcer, news reader, and reporter.

In addition, related to the student's fluency and accuracy in speaking, $72 \%$ students agree that they can speak more fluent and their accuracy become better because in a workshop on radio class, they train to be aware to their speaking. Finally, $60 \%$ agree that by practicing as a radio announcer, news reader and reporter, their self-confident is improve. 


\section{CONCLUSION}

Based on the finding, it can be concluded that the implementation of Workshop on Radio Broadcasting class gives positive effects on students speaking ability. However, the results are out of expectation. In the beginning of the research, it is hoped that the Workshop on Radio Broadcasting class can give significant improvement to the students' speaking ability. In fact, the data shows that the improvement is not really significant. Therefore, there are some commendations can be given. First, the Workshop on Radio Broadcasting lectures should conduct the advance research to know the comprehensive results. Second, the Workshop on Radio Broadcasting lectures have to evaluate the syllabus, the teaching materials, and methods.

\section{BIBLIOGRAPHY}

Brown, H. D. (2001). Teaching by Principles An Interactive Approach to Language Pedagogy (2nd ed.). New York: Longman.

d'Ecclesia, G. (2013). Theories and Techniques of Radio Broadcasting. Retrieved from info@radiobroadcaster.org

Hughes, A. (1989). Testing for language teachers. Cambridge and New York: Cambridge University Press ix.

Mohammed, J. (2013). Challenges and Opportunities in the Use of Radio Broadcast for Development in Ethiopia: Secondary Data Analysis. Online Journal of Communication and Media Technologies, 3(2).

Nunan, D. (2003). Practical English Language Teaching (1st ed.). Singapore: Mc.Graw Hill.

Wallace, T., Stariba, W. ., \& Walberg, H. J. (2004). Teaching Speaking, Listening and Writing. Retrieved from http://www.curtin.edu.au/curtin/dept/smec/iae 